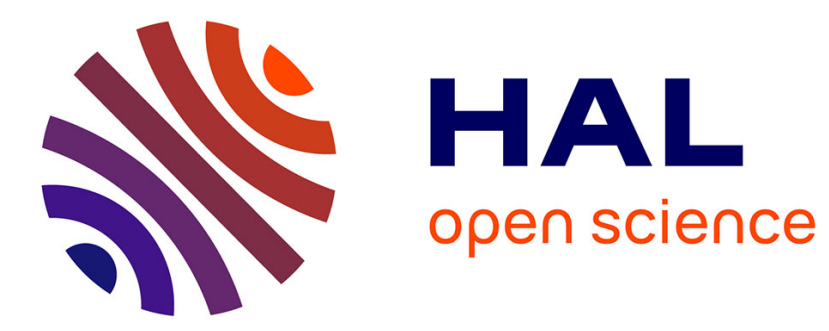

\title{
Ion extraction mechanism studied in a lyotropic lamellar phase
}

\author{
Amélie Banc, P. Bauduin, Bernard Desbat, Isabelle Ly, Olivier Diat
}

\section{To cite this version:}

Amélie Banc, P. Bauduin, Bernard Desbat, Isabelle Ly, Olivier Diat. Ion extraction mechanism studied in a lyotropic lamellar phase. Journal of Physical Chemistry B, 2011, 115 (6), pp.1376-1384. 10.1021/jp108585f . hal-00578376

\section{HAL Id: hal-00578376 https://hal.science/hal-00578376}

Submitted on 21 Mar 2011

HAL is a multi-disciplinary open access archive for the deposit and dissemination of scientific research documents, whether they are published or not. The documents may come from teaching and research institutions in France or abroad, or from public or private research centers.
L'archive ouverte pluridisciplinaire HAL, est destinée au dépôt et à la diffusion de documents scientifiques de niveau recherche, publiés ou non, émanant des établissements d'enseignement et de recherche français ou étrangers, des laboratoires publics ou privés. 


\title{
Ion extraction mechanism studied in a lyotropic lamellar phase
}

\author{
Amélie Banc ${ }^{\dagger}$, Pierre Bauduin ${ }^{\dagger}$, Bernard Desbat ${ }^{\S}$, Isabelle Ly $y^{\ddagger}$, Olivier Diat ${ }^{\dagger *}$ \\ †Institut de Chimie Séparative de Marcoule, UMR 5257 (CEA/CNRS/UM2/ENSCM), BP 17171, F-30206 Bagnols sur Cèze, \\ France \\ ${ }^{\S}$ Université Bordeaux-1, Laboratoire de Chimie et Biologie des Membranes et Nanoobjets, UMR 5248-CNRS, ENITAB, 2 \\ rue Robert Escarpit, F-33607 Pessac, France \\ *Université Bordeaux-1 CNRS, Centre de Recherche Paul-Pascal, UPR 8641, 115 avenue A. Schweitzer, F-33600 Pessac,
} France

\begin{abstract}
In this paper we used a surfactant-stabilized lyotropic lamellar model system to study the interfacial behaviour of an ion-extracting agent: $\mathrm{N}^{1}, \mathrm{~N}^{3}$ dimethyl- $\mathrm{N}^{1}, \mathrm{~N}^{3}$-dibutyl-2-tetradecyl malonamide (DMDBTDMA). An analysis of small angle X-ray scattering (SAXS) and polarized Attenuated Total Reflectance - Fourier Transform Infra Red (ATR-FTIR) data enabled to describe the distribution of the malonamide extractant within the bilayers and its complexation state at the equilibrium. The lamellar phase was diluted with salt water containing varying amount of complexing salt, and each structural state measured was described using a thermodynamic model based on three elementary equilibria: (i) partition of the extractant polar heads between the core and the polar shell of the bilayers, (ii) the complexation of ions by extractants at the bilayers surfaces, and (iii) the partition of bonded extractants between the core and interfaces of bilayers. This model enabled to compare the energy cost of each step.
\end{abstract}

\section{INTRODUCTION}

Reactions at liquid-liquid interfaces are of great fundamental interest because they play a key role in many important chemical and biological systems ${ }^{1}$, such as phasetransfer catalysis $^{2}$, liquid-liquid extraction, micellar catalysis $^{3}$, biomembrane activity, enzymatic reactions on fat lipases ${ }^{4}$. Systems in which such reactions take place are difficult to study because their global behaviour is the result of reactants diffusion in bulk and interfacial mechanisms. To study specifically liquid interfaces, different experimental systems were developed: systems with a unique and controlled interface between two immiscible liquids (interface of pendant drops ${ }^{5}$, interface developed for reflectance measurements ${ }^{6}$, interface created into a microchannel $^{7}$, nanoscopic interface supported by nanopipette $^{8}$, and systems with interfaces stabilized by amphiphilic molecules (vesicles ${ }^{9}$, micelles and microemulsions ${ }^{10}$ ). In the present work, we chose to use lyotropic lamellar phases, periodical stacking of oily layers (made by the surfactant tails) diluted by salt water. These systems with multiple interfaces, in thermodynamic equilibrium, are structurally and mechanically responsive to weak effects, such as the Hofmeister ion effect ${ }^{11,12,13}$ or the partitioning of host molecules within bilayers ${ }^{14,15,16,17}$. In a previous paper $^{18}$ we described and characterized the insertion of a lipophilic ion-complexing agent, $\mathrm{N}^{1}, \mathrm{~N}^{3}$ dimethyl- $\mathrm{N}^{1}, \mathrm{~N}^{3}$ dibutyl-2-tetradecyl malonamide (DMDBTDMA), in a lamellar phase stabilized by a non-ionic surfactant: pentaethyleneglycol dodecyl ether $\left(\mathrm{C}_{12} \mathrm{E}_{5}\right)$. DMDBTDMA is an extractant molecule used in nuclear industry to separate minor actinides from high level radioactive liquid wastes by liquid-liquid extraction processes ${ }^{19}$ (DIAMEX process) or in more conventional hydrometallurgy for the rare earths elements recycling ${ }^{20,21}$. We showed that the structural parameters of an ideal lamellar system enabled to describe the partition of the extractant molecules between the core and the interface of bilayers. This simple approach was based on the evolution of interfacial area with the addition of extractants, which was measurable thanks to the multitude of interfaces in lamellar phases, as for microemulsion systems ${ }^{22}$.

In the present paper, we studied the effect of ion complexation on the system. First, we characterized the system using Small Angle X-Ray Scattering (SAXS) and transmission electron microcopy (TEM) coupled with freeze fracture to follow structural parameters, and polarized Attenuated Total Reflectance - Fourier Transform Infra Red (ATR-FTIR) spectroscopy to measure orientation of dipoles and to quantify the ion complexation phenomenon. In a second part, a thermodynamic approach of liquid-liquid extraction was developed on the basis of the experimental data by considering the ion extraction process as the sum of three equilibria (Scheme 1):

(1) Positioning of free extractants polar head areas at interfaces

(2) Complexation of cations with extractants at interfaces

(3) Burying of bonded extractants within the bilayers Hence, the free energy contributions of each step was estimated and compared. This allowed to elucidate the precise mechanism of extraction by DMDBTDMA in this model system.

\section{EXPERIMENTAL SECTION}

$\mathrm{C}_{12} \mathrm{E}_{5}$ was obtained from Nikko Ltd. (high purity grade > 99\%) and used as received. DMDBTDMA was obtained from Panchim and was purified on an alumina column to eliminate traces of surface active impurities. Aqueous solutions were prepared using deuterated water (99.9\%, Eurisotop), anhydrous $\mathrm{LiNO}_{3}$ salt (purity>99\%) from Strem, and $\mathrm{Nd}\left(\mathrm{NO}_{3}\right)_{3}, 6 \mathrm{H}_{2} \mathrm{O}$ salt (purity>99.9\%) from Aldrich. 


\section{OIL PHASE}

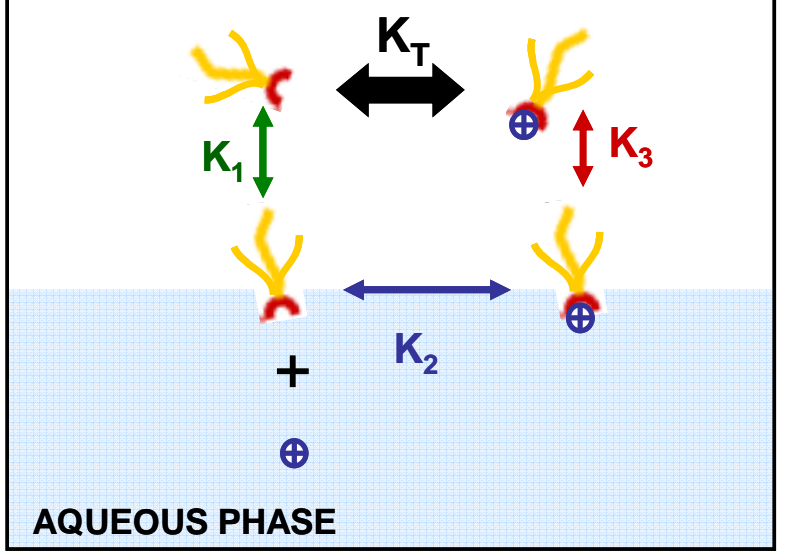

Scheme 1. Schematic view of cation extraction by extractant molecules. The global extraction reaction $\left(\mathrm{K}_{\mathrm{T}}\right)$ can be divided into three elementary mechanisms which are characterized by thermodynamic equilibrium constants: Adsorption of extractants from the organic phase to the interface $\left(\mathrm{K}_{1}\right)$, complexation of cations with extractants which are at the interface $\left(\mathrm{K}_{2}\right)$, and desorption of ionextractant complex from the interface to the organic phase $\left(\mathrm{K}_{3}\right)$.

To avoid introduction of $\mathrm{H}_{2} \mathrm{O}$ into samples, hydration water molecules of the neodymium salt were exchanged by $\mathrm{D}_{2} \mathrm{O}$ performing five $\mathrm{D}_{2} \mathrm{O}$ solubilisation (stirring at $50^{\circ} \mathrm{C}$ ) drying (under vacuum) cycles under inert atmosphere (Ar). The efficiency of the exchange was checked by FTIR looking at the disappearance of the $\mathrm{OH}$ stretching mode around $3400 \mathrm{~cm}^{-1}$. Samples were formulated adding the deuterated solutions to a premix of $\mathrm{C}_{12} \mathrm{E}_{5} / \mathrm{DMDBTDMA}$ (80/20 molar). Sample were homogenised with a succession of centrifugations and were left several days at $25^{\circ} \mathrm{C}$ to reach equilibrium. Dodecane (purity> 90\%, Fluka) used for tensiometry experiments was previously purified on an alumina column.

Microscopic observations were performed on a Zeiss Axio Imager A1m microscope equipped with crossed polarisers. To determine conditions of homeotropic orientation of lamellar samples (bilayers oriented perpendicular to the optical axis), different thicknesses of spacers between glass slide and cover slip were tested. It was observed that samples sheared between slide and cover slip spaced by $10 \mu \mathrm{m}$ thick mica sheets, display homeotropic orientation after few minutes (Figure 1).

For freeze-fracture measurements, a drop of sample was placed on a gold holder and frozen by plunging into liquid propane. Fracture and replication were carried out in a freeze-fracture apparatus (Leica EM BAF060) at the temperature of $-150{ }^{\circ} \mathrm{C}$ under vacuum. $\mathrm{Pt} / \mathrm{C}$ was deposited at an angle of $45^{\circ}$ and $\mathrm{C}$ at $90^{\circ}$. Replicas were recovered at room temperature by specimen dissolution in ethanol and water. Then, replicas were collected onto ATHENE copper 400 mesh grids to be examined on an Hitachi H-600 $75 \mathrm{kV}$ 's transmission electron microscope equipped with an AMT's CCD camera (DVC 1 megapixels).
Small angle X-ray scattering (SAXS) measurements using Mo-radiation $(\lambda=0.71 \AA$ ) were performed on a bench built by XENOCS. The scattered beam was recorded using a large online scanner detector (diameter: $345 \mathrm{~mm}$, from MAR Research) located at $750 \mathrm{~mm}$ from the sample stage. A large $Q$ range $\left(2.10^{-2}-2.5 \AA^{-1}\right)$ was covered thanks to an off centre detection. The collimation was applied using a 12:œ multilayer Xenocs mirror (for Mo radiation) coupled to two sets of scatterless FORVIS slits ${ }^{23}$ providing a $0.8 \mathrm{x}$ $0.8 \mathrm{~mm} x$-ray beam at the sample position. Pre-analysis of data was performed using FIT2D software, taking into account the electronic background of the detector (the flatfield is homogeneous) and the empty cell subtraction. The scattered intensities were expressed versus the magnitude of scattering vector $Q=[(4 \pi) / \lambda] . \sin (\theta / 2)$, where $\lambda$ is the wavelength of incident radiation and $\theta$ the scattering angle. Experimental resolution was $\Delta \mathrm{Q} / \mathrm{Q}=0.05$. Silver behenate in a sealed capillary was used as the scattering vector calibration standard. The lamellar periodicity of samples (d) was deduced from the first Bragg peak position $\mathrm{Q}_{0}$ :

$$
d=\frac{2 \Pi}{Q_{0}}
$$

Surface tension experiments at the oil-water interface were performed on pendant drops using a drop shape analyser (Kruss DSA 100). The aqueous solution was either $\mathrm{LiNO}_{3}$ $1 \mathrm{M}$ or $\mathrm{Nd}\left(\mathrm{NO}_{3}\right)_{3} \quad 0.33 \mathrm{M}$, and organic solutions were DMDBTDMA solubilized into dodecane (from 0.005 to $1 \mathrm{M})$. Before tensiometry measurements, each organic solution was emulsified with the aqueous solution of interest $(50 / 50 \mathrm{v} / \mathrm{v})$ by mechanical stirring for 2 minutes and then isolated after centrifugation. Densities of solutions were measured at $20^{\circ} \mathrm{C}$ using a vibrating tube densimeter, DSA 5000 from Anton Paar. After injection of the organic drop into the aqueous solution, surface tension was measured versus time. The values at equilibrium $(<1 \%$ evolution) were selected for this study. The Gibbs equation was used to calculate the superficial excess of extractant $(\Gamma)$ :

$$
\Gamma=-\frac{1}{R T}\left(\frac{\partial \gamma}{\partial \ln C}\right)_{T, P}
$$

where $\gamma$ is the surface tension and $\mathrm{C}$ is the concentration of the adsorbing specie (in the concentration region below $\mathrm{cmc}$ ). Hence, the polar head area (A) was determined using:

$$
A=\frac{1}{N_{a} \Gamma}
$$

where $\mathrm{N}_{\mathrm{a}}$ is the Avogadro constant.

Polarized ATR-FTIR experiments were performed on a Perkin Elmer Spectrum-One Fourier Transform Infrared system equipped with an attenuated total mono reflection (ATR) device, using a diamond crystal. Lamellar phase samples, spread on the ATR crystal, were confined under a glass coverslip, $10 \mu \mathrm{m}$-spaced from the crystal (Figure 1).

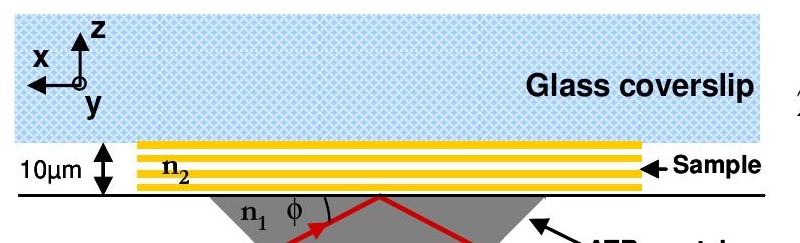


Figure 1. Polarized FTIR-ATR. (a) Scheme of the experimental setup. The sample was confined between the ATR crystal and a glass cover slip to ensure an homeotropic orientation of the lamellar phase. Polarized light microscopy pictures of samples observed 1 minute (b) and 5 minutes (c) after shearing between flat surfaces separated by $10 \mu \mathrm{m}$.

This confinement ensured the orientation of the lamellar phase (bilayers parallel to the crystal) as demonstrated by polarized light microscopy and a sample thickness higher than the penetration depth of the evanescent electromagnetic waves, $d_{p}$, defined by ${ }^{24}$ :

$$
d_{p}=\frac{\lambda}{2 \pi n_{1} \sqrt{\left(\sin ^{2} \Phi-n_{21}^{2}\right)}}
$$

where $\Phi$ is the incidence angle, $\lambda$ is the wavelength, $\mathrm{n}_{1}$ is the refractive index of the ATR crystal, $\mathrm{n}_{2}$ the refractive index of the sample, and $n_{21}=n_{2} / n_{1}$. In our case, $d_{p}$ varied between 0.2 and $1 \mu \mathrm{m}\left(\mathrm{n}_{1}=2.4, \mathrm{n}_{2}=1.45\right.$ and $\left.\Phi=45^{\circ}\right)$. For each sample, 64 scans spectra, with a resolution of $4 \mathrm{~cm}^{-1}$, were obtained for two polarizations of the incident beam: parallel (p) and perpendicular (s) to the incidence plane. A linear baseline correction was performed on each spectrum. Two kinds of analysis were performed with FTIR data: first, to obtain information about orientation of dipoles into samples, and second to quantify bonded extractants. Orientation information of dipoles is contained in the dichroic ratio $\mathrm{R}^{\mathrm{ATR}}$ which is the ratio of the absorbance of the corresponding band measured with a parallel polarization of the incident light $A_{p}$ to the absorbance measured with a perpendicular polarization $\mathrm{A}_{\mathrm{s}}$ :

$$
\mathrm{R}^{\mathrm{ATR}}=\frac{A_{p}}{A_{s}}
$$

The dichroic ratio is related to the dipole order parameter $\mathrm{S}$, according to:

$$
S=\frac{\left(E_{x}^{2}-R^{A T R} E_{y}^{2}+E_{z}^{2}\right)}{\left(E_{x}^{2}-R^{A T R} E_{y}^{2}-2 E_{z}^{2}\right)}
$$

where $\mathrm{E}_{\mathrm{x}}{ }^{2}, \mathrm{E}_{\mathrm{y}}{ }^{2}$ and $\mathrm{E}_{\mathrm{z}}{ }^{2}$ are the time-averaged square electric field amplitudes of the evanescent wave in the sample at the crystal/sample interface. The electric field amplitudes on the crystal-sample interface were calculated using the thick film model of Harrick ${ }^{25}$, valid when the thickness of the sample is very large compared to the penetration depth:

$$
\begin{gathered}
E_{x}^{2}=\frac{4 \cos ^{2} \Phi \cdot\left(\sin ^{2} \Phi-n_{21}^{2}\right)}{\left(1-n_{21}^{2}\right)\left[\left(1+n_{21}^{2}\right) \sin ^{2} \Phi-n_{21}^{2}\right]} \\
E_{y}^{2}=\frac{4 \cos ^{2} \Phi}{\left(1-n_{21}^{2}\right)} \\
E_{z}^{2}=\frac{4 \cos ^{2} \Phi \sin ^{2} \Phi}{\left(1-n_{21}^{2}\right)\left[\left(1+n_{21}^{2}\right) \sin ^{2} \Phi-n_{21}^{2}\right.}
\end{gathered}
$$

In our case, $\mathrm{E}_{\mathrm{x}}=1.157, \mathrm{E}_{\mathrm{y}}=1.774$ and $\mathrm{E}_{\mathrm{z}}=2.227$.

The order parameter $\mathrm{S}$ contains the information on the mean orientation of the transition dipole and on the distribution of the dipole orientations at the mean value:

$$
S=\frac{3\left\langle\cos ^{2} \theta\right\rangle-1}{2}
$$

where $\theta$ is the angle between the dipole and the normal of the ATR plate, and $\left\langle\cos ^{2} \theta\right\rangle$ is the mean value of $\cos ^{2} \theta$ for a distribution of transition moment in the film.

To perform quantitative analysis of bonded extractants, the isotropic spectrum of samples was calculated from the polarized spectra. The isotropic sprectrum can be defined as:

$$
\mathrm{S}_{\text {iso }}=\mathrm{S}_{\mathrm{x}}+\mathrm{S}_{\mathrm{y}}+\mathrm{S}_{\mathrm{z}}
$$

where $S_{i}$ is the spectrum in the direction $i$. The sample being uniaxial, $S_{x}=S_{y}$. Polarized spectra can be defined as follow:

$$
\mathrm{S}_{\mathrm{s}}=\mathrm{E}_{\mathrm{x}} \cdot \mathrm{S}_{\mathrm{x}} \text { and } \mathrm{S}_{\mathrm{p}}=\mathrm{E}_{\mathrm{y}} \cdot \mathrm{S}_{\mathrm{y}}+\mathrm{E}_{\mathrm{z}} \cdot \mathrm{S}_{\mathrm{z}}
$$

Hence using our parameters,

$$
\mathrm{S}_{\mathrm{iso}}=0.8345 . \mathrm{S}_{\mathrm{s}}+0.449 . \mathrm{S}_{\mathrm{p}}
$$

The second analysis was related to the ion-bonding of extractants and was studied using the carbonyl band positioned around $1650 \mathrm{~cm}^{-1}$. This band was fitted using two Gaussian curves centred at 1640 and $1615 \mathrm{~cm}^{-1}$ assigned to free carbonyls (not complexed) and bonded carbonyls (complexed with $\mathrm{Nd}^{3+}$ ) respectively. Fitting procedure was realised with the Omnic software which uses a Fletcher-Powell-McCormick algorithm as convergence routine. To obtain the area of each contribution, positions and the full widths at half height were fixed and maintained constant for all samples. The evolution of the free carbonyl absorbance (area) in isotropic spectra enabled to quantify the complexation into samples. According to the BeerLambert law:

$$
\mathrm{A}=\varepsilon . l . \mathrm{C}(14)
$$


where $\mathrm{A}$ is the absorbance, $l$ the length of the pathway, $\mathrm{C}$ the concentration, and $\varepsilon$ the extinction coefficient. Considering that for a vibration mode $\varepsilon$ is constant, and that 1 is constant in our samples (the sample thickness is higher than the penetration depth which is constant for given wavelength and setup), the following relationship can be established:

$$
\left(\mathrm{A}_{0}-\mathrm{A}\right) / \mathrm{A}_{0}=\left(\mathrm{C}_{0}-\mathrm{C}\right) / \mathrm{C}_{0}
$$

Hence, the fraction of free carbonyl consumed (bonded carbonyls created) was determined.

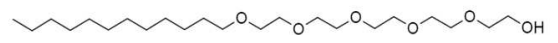

(a)

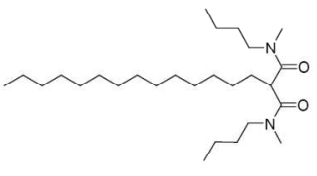

(b)

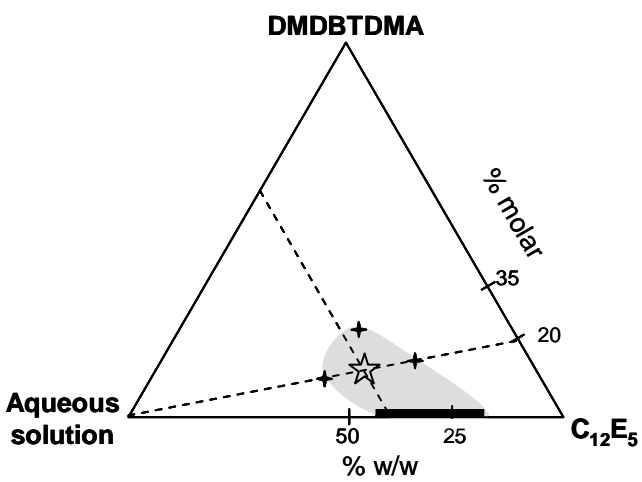

Figure 2. Molecular $\stackrel{(\mathrm{c})}{\text { structures of }} \mathrm{C}_{12} \mathrm{E}_{5}$ (a) and DMDBTDMA (b). (c) Ternary phase diagram of $\mathrm{C}_{12} \mathrm{E}_{5} / \mathrm{DMDBTDMA} /$ aqueous solution indicating in grey the monophasic lamellar phase domain at room temperature. The salty aqueous solution contains $\mathrm{LiNO}_{3}$ and $\mathrm{Nd}\left(\mathrm{NO}_{3}\right)_{3}$ salts in a 1 molar ionic strength. Crosses indicate experimental points and the star indicates the composition of samples studied in this paper $\left(\mathrm{C}_{12} \mathrm{E}_{5} / \mathrm{DMDBTDMA}=80 / 20\right.$ molar, $40 \%$ hydration $)$.

\section{RESULTS}

Preliminary experiments were carried out to identify the boundaries of the monophasic lamellar phase in the ternary phase diagram $\mathrm{C}_{12} \mathrm{E}_{5}$ /DMDBTDMA/aqueous solution (1M). Macroscopic and microscopic (optical microscopy with crossed polarizers) observations performed on some formulations, derived from the lamellar domain of the surfactant/water system ${ }^{26}$, enabled to roughly determine the lamellar region in the ternary system (Fig. 2). In the present work, we choose to work with a formulation located at the center of this domain: a premix $\mathrm{C}_{12} \mathrm{E}_{5}$ /DMDBTDMA 80/20 molar hydrated with $40 \mathrm{wt} \%$ of aqueous solution. This composition lies in the concentrated region of the lamellar phase (aqueous layers are about $2 \mathrm{~nm}$ thick) mainly stabilized by the interplay of the attractive van der Waals force and the steric repulsion of the hydrated head groups (repulsive undulation forces are negligible) ${ }^{27}$. The effect of complexation was studied varying the nature of the aqueous solution from $\mathrm{LiNO}_{3} 1 \mathrm{M}$ to $\mathrm{Nd}\left(\mathrm{NO}_{3}\right)_{3} \quad 0.33 \mathrm{M}$ to keep 1 molar of ionic strength (range of ionic strength applied in extraction systems) in the different samples.

The lamellar phases obtained with such formulations were characterized by freeze-fracture (see Figure 3). A characteristic lamellar structure with periodical steps, was obtained for both $\mathrm{LiNO}_{3}$ or $\mathrm{Nd}\left(\mathrm{NO}_{3}\right)_{3}$ hydrated extractantcontaining lamellar phases, like for the binary system. No structural change e.g. topological defects ${ }^{28}$ was detected after addition of extractant or salt to the lamellar phase.

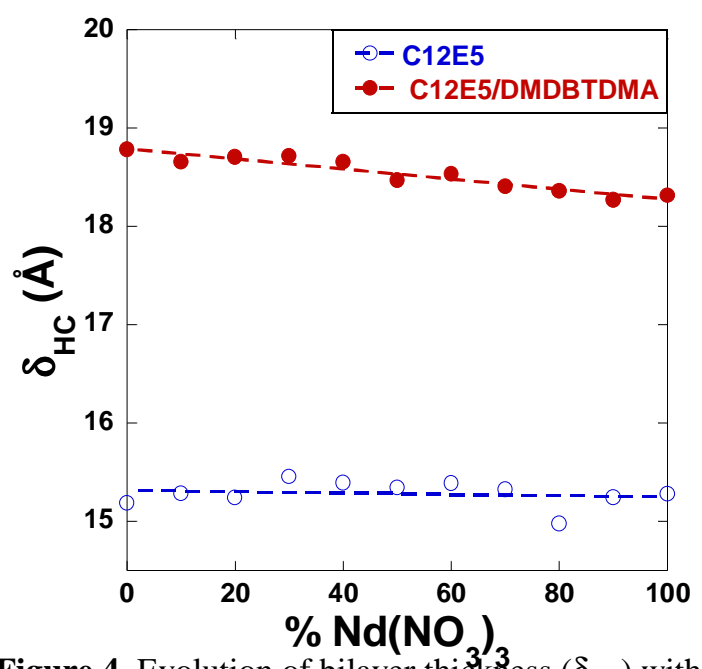

Figure 4. Evolution of bilayer thickness $\left(\delta_{\mathrm{HC}}\right)$ with the percentage of $\mathrm{Nd}\left(\mathrm{NO}_{3}\right)_{3}$ in the aqueous solution. Empty dots display the reference system $\left(\mathrm{C}_{12} \mathrm{E}_{5}\right)$ whereas full dots display the mixed system $\mathrm{C}_{12} \mathrm{E}_{5}$ /DMDBTDMA (80/20 molar).

The periodicity (d) of samples was characterized using SAXS. Assuming an ideal lamellar structure (flat rigid bilayers without defect), the hydrocarbon thickness of bilayers $\left(\delta_{H C}\right)$ was determined using the following dilution law:

$$
\delta_{\mathrm{HC}}=d \cdot \Phi_{H C}
$$
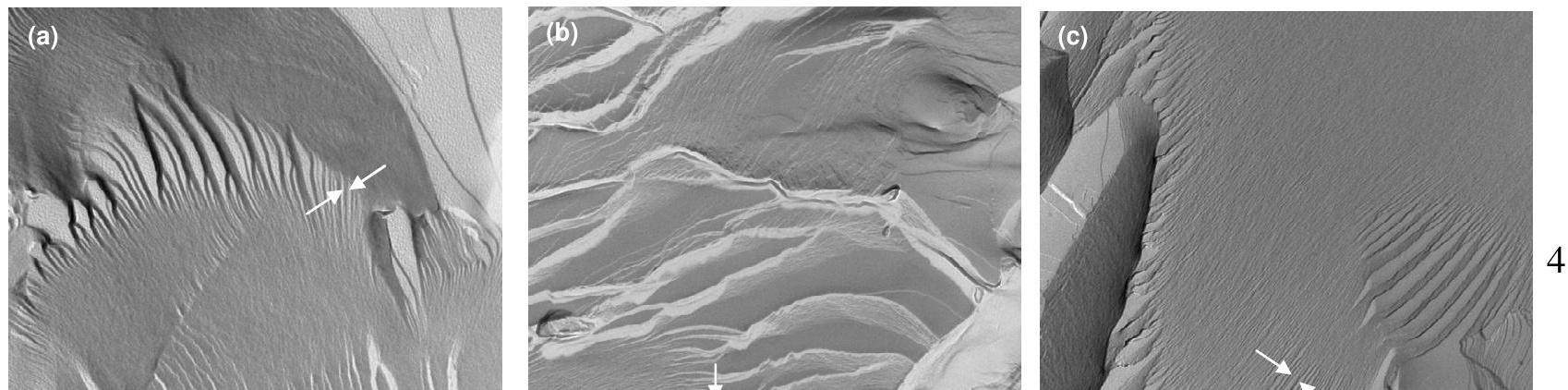
Figure 3. TEM pictures of freeze-fracture replica: (a) $\mathrm{C}_{12} \mathrm{E}_{5}$ lamellar phase hydrated with $30 \% \mathrm{LiNO}_{3} 1 \mathrm{M}$, (b) $\mathrm{C}_{12} \mathrm{E}_{5} / \mathrm{DMDBTDMA}$ lamellar phase hydrated with $40 \% \mathrm{LiNO}_{3}(1 \mathrm{M})$, and (c) $\mathrm{C}_{12} \mathrm{E}_{5} / \mathrm{DMDBTDMA}$ lamellar phase hydrated with $40 \% \mathrm{Nd}\left(\mathrm{NO}_{3}\right)_{3}(0.33 \mathrm{M})$.

where $\phi_{H C}$ is the volume fraction of DMDBTDMA and alkyl chains of $\mathrm{C}_{12} \mathrm{E}_{5}$ in the sample. The following density values were used: $\mathrm{d}_{\mathrm{C} 12}=0.803^{29}, \mathrm{~d}_{\mathrm{C} 12 \mathrm{E} 5}=0.963$ (from supplier) and $\mathrm{d}_{\text {DMDBTDMA }}=0.906$ (measured). The interface was defined as being located between the aliphatic chains of surfactants, and the polar layer comprising the polar heads of surfactants and hydration water. Figure 4 displays the evolution of bilayer thickness versus the neodymium percentage in the hydration solution for $\mathrm{C}_{12} \mathrm{E}_{5}$ and $\mathrm{C}_{12} \mathrm{E}_{5} / \mathrm{DMDBTDMA}$ lamellar phases. By increasing the neodymium content, the bilayer thickness remains constant for the reference $\mathrm{C}_{12} \mathrm{E}_{5}$ samples, whereas it continuously decreases from 18.8 to $18.3 \AA$ for samples containing DMDBTDMA.

In our previous paper ${ }^{18}$, we demonstrated in analysing the bilayer thicknesses that the extractant molecule can be considered either as a co-surfactant or as a solvent molecule distributed within the aliphatic domain of the bilayers, both configurations being in equilibrium for a given surfactant/extractant ratio. Assuming an ideal mixing of extractant and surfactant, and constant polar areas per molecule at the hydrophilic/hydrophobic interface, the bilayer thickness was expressed as a function of the extractant repartition between the interfaces and the bulk of the bilayers:

$$
\delta_{H C}=\frac{V}{A}=2 \frac{(1-x) V_{C_{12}}+x V_{\text {DMDBTDMA }}}{(1-x) A_{C_{12} E_{5}}+x K A_{D M D B T D M A}}
$$

where $V_{i}$ are molecular volumes determined from density values, $A_{i}$ are polar head areas, $x$ is the molar fraction of DMDBTMA among the organic components and $\kappa$ the fraction of DMDBTDMA participating to the interfacial area. The two extreme cases, $\kappa=0$ and $\kappa=1$, are plotted on Figure 5. The experimental points are intermediate $(0<\kappa<1)$ and indicate roughly an equi-partitioning of extractant molecules between the core of the bilayers and the interfaces. The decrease of $\delta_{\mathrm{HC}}$ with the percentage of complexing ions can be thus interpreted as an evolution of extractants partition within the bilayers; qualitatively, the interaction between extractant molecules and ions that can be complexed, pull the lipophilic extractants towards the interface.

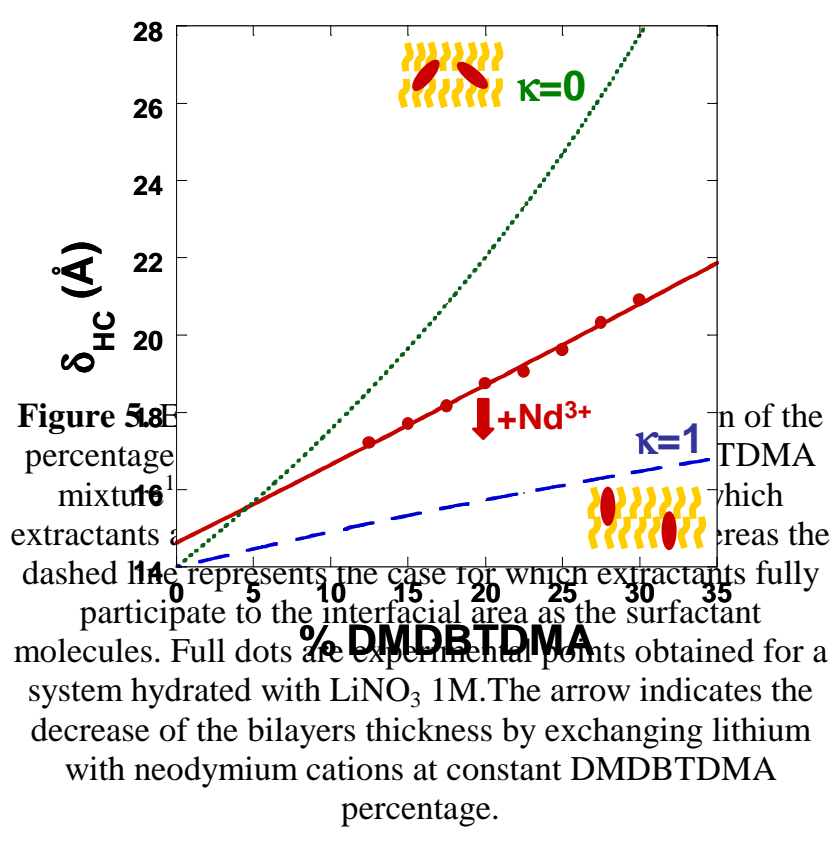

To estimate the contribution of extractants to the interfacial area we measured their polar head area at model oil-water interfaces: dodecane- $\mathrm{LiNO}_{3} \quad 1 \mathrm{M}$ and dodecane- $\mathrm{Nd}\left(\mathrm{NO}_{3}\right)_{3}$ $0.33 \mathrm{M}$, to consider free and bonded extractants respectively. Dodecane was chosen to mimic the $\mathrm{C}_{12}$ chain of surfactants which constitute the oily domains. Figure 6 displays the evolution of interfacial tensions versus DMDBTDMA concentration for both cases. Critical aggregation concentrations around $0.1 \mathrm{M}$ can be noticed, in accordance with literature ${ }^{30,31}$. Using the Gibbs equation (2), we obtained $\mathrm{A}_{\text {free }}$ DMDBTDMA $=80 \pm 5 \AA^{2} /$ molecule and $A_{\text {bonded DMDBTDMA }}=100 \pm 5 \AA^{2} /$ molecule. These values do not represent only a geometrical polar area but takes into account all the lateral interactions within the bilayers. Ion complexation charges the extractant molecules and induces additional electrostatic lateral repulsions that consequently increase the apparent extractant polar head area.

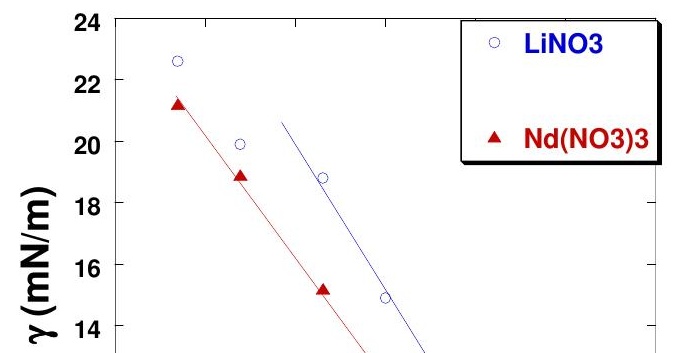


Figure 6. Determination of polar-head areas of free and bonded DMDBTDMA by tensiometry measurements. Free DMDBTDMA is studied using an aqueous solution of $\mathrm{LiNO}_{3} 1 \mathrm{M}$, whereas bonded DMDBTDMA is studied using a $0,3 \mathrm{M} \mathrm{Nd}\left(\mathrm{NO}_{3}\right)_{3}$ solution.

Figure 7 displays the characteristic polarized ATR-FTIR spectra of oriented samples. We can notice the large OD elongation vibrations around $2500 \mathrm{~cm}^{-1}$, the $\mathrm{OH}$ elongation vibrations attributed to the polar head of surfactants around $3400 \mathrm{~cm}^{-1}$, the $\mathrm{CH}_{2}$ vibration modes around $2900 \mathrm{~cm}^{-1}$, and

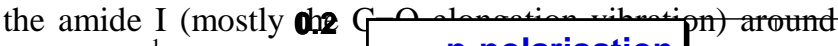
$1650 \mathrm{~cm}^{-1}$. The symm - p-polarisation of $\mathrm{CH}_{2}$, positioned at $2855 \mathrm{~cm}^{-1}\left(-\mathbf{s}\right.$-polarization ${ }_{\text {probe the }} \mathbf{v o p}$ order of aliphas $\mathbf{Q} \mathbf{1 5}$ ins into bilayers, whereas the $\mathrm{C}=\mathrm{O}$ elongation vibraion mode was used to probe extractant
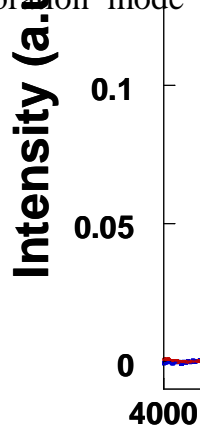

molecules. This latter was decomposed into two main contributions centred at 1640 and $1615 \mathrm{~cm}^{-1}$ attributed to free $\left(v_{\mathrm{C}=\mathrm{O}_{f}}\right)$ and bonded $\left(v_{\mathrm{C}=\mathrm{O}_{b}}\right)$ carbonyls respectively.

Hence, we calculated the dichroic ratios corresponding to $v_{\mathrm{CH}_{2 S}}, v_{\mathrm{C}=\mathrm{O}_{f}}, v_{\mathrm{C}=\mathrm{O}_{b}}$. These ratios are constant whatever the neodymium percentage and the mean values are displayed in Table 1. As the transition moment for the $v_{\mathrm{CH}_{2 S}}$ lies perpendicular to the chain axis, the order parameter of aliphatic chains was calculated using the following relationship:

$$
S=\frac{2\left(E_{x}^{2}-R^{A T R} E_{y}^{2}+E_{z}^{2}\right)}{\left(3 \cos ^{2} \alpha-1\right)\left(E_{x}^{2}-R^{A T R} E_{y}^{2}-2 E_{z}^{2}\right)}
$$

where $\alpha$ is the angle between the chain axis director and the transition dipole $\left(\alpha=90^{\circ}\right)$. The low value obtained $(S=0.1)$ is explained by the fluid character of the $\mathrm{L}_{\alpha}$ bilayers and is consistent with literature results for $\mathrm{C}_{12} \mathrm{E}_{5}$ /water lamellar phases $^{32}$. The zero value of $S$ for free carbonyls indicates an isotropic orientation of these bonds, as previously measured usirigs polarized microRaman spectroscopy ${ }^{18}$, contrary to bonded carbonyls which are characterized by a value close to that of aliphatic

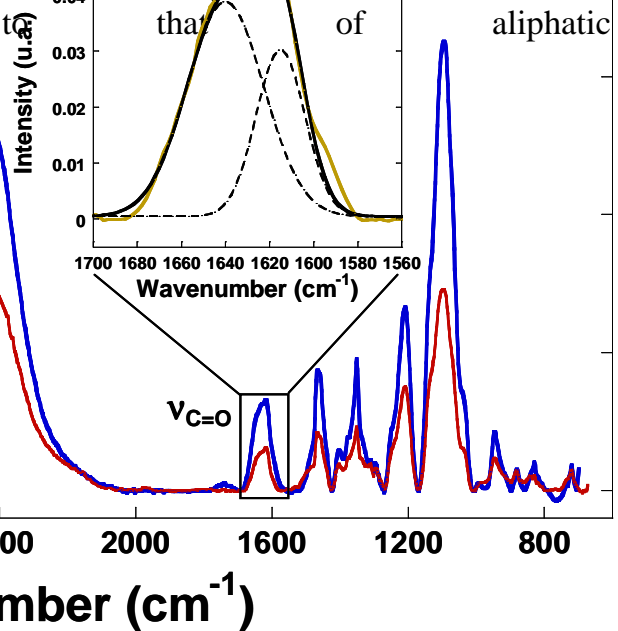

Figure 7. Polarized ATR-FTIR spectra of samples. The carbonyl band was decomposed into two mains contributions centred at $1640 \mathrm{~cm}^{-1}$ and $1615 \mathrm{~cm}^{-1}$ (in inset, yellow line : experimental spectrum, full dark line: fitted spectrum).
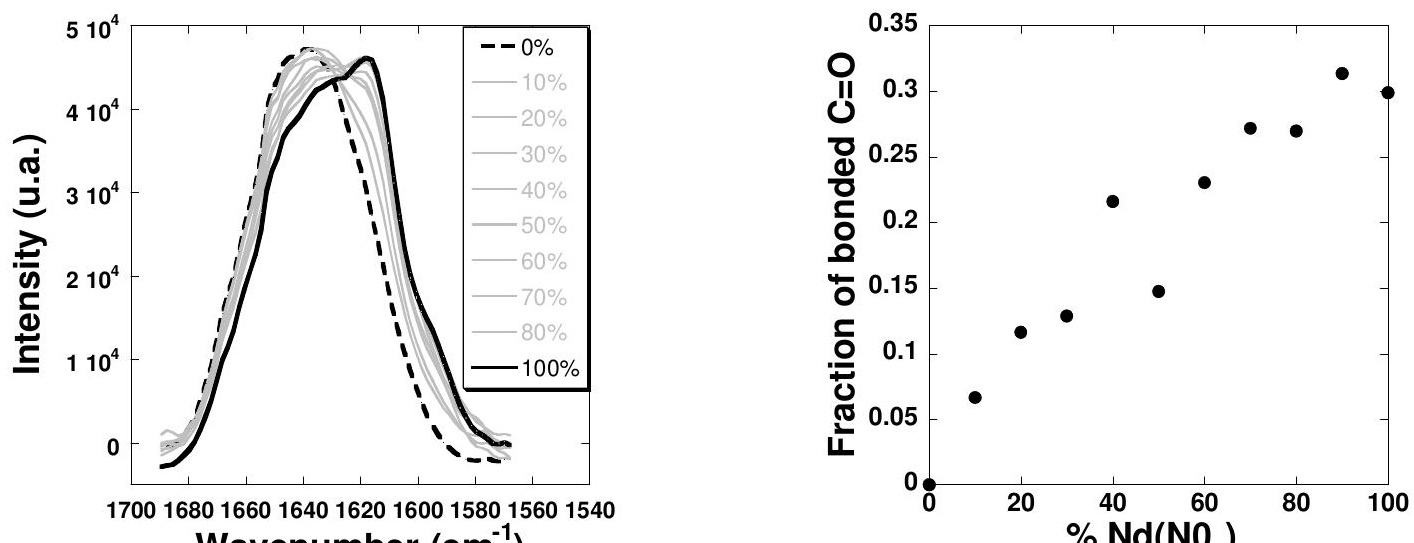
Figure 8. (a) Evolution of the carbonyl stretching vibration band with the percentage of neodynium salts in the aqueous solution. (b) Fraction of bonded carbonyl versus the percentage of neodymium obtained using equation (15).

This result must be analysed considering that the experimental order parameter measured from $\mathrm{R}^{\mathrm{ATR}}$, denoted $\mathrm{S}_{\mathrm{exp}}$, is the product of several order parameters related to a set of nested, uniaxial symmetric distributions ${ }^{33,34}$ :

$$
\mathrm{S}_{\text {exp }}=\mathrm{S}_{\text {membrane }} \mathrm{S}_{\text {molecule }} \mathrm{S}_{\text {dipole }}
$$

where $S_{\text {memb }}$ describes the distribution function of the membrane patches with respect to the internal reflection element, $S_{\text {molecule }}$ describes the orientation of the molecules within the membrane plane, and $S_{\text {dipole }}$ describes the orientation of the dipole relative to the molecule. Providing the good orientation of the samples sheared between $10 \mu \mathrm{m}$ spaced flat surfaces, we can estimate that $S_{\text {membrane }}$ is close to 1 . Hence, the variation of order parameter with complexation can be attributed either to a change of molecule orientation inside bilayers $\left(S_{\text {molecule }}\right)$ or a modification of carbonyls orientation with respect to the molecule axis $\left(S_{\text {dipole }}\right)$. It is difficult to consider a higher order parameter for the extractant compared to the one of the surfactant $(\mathrm{S}=0.1)$. Then, with $\mathrm{S}_{\mathrm{C}=\text { Obonded }}=0.096$ and considering $\mathrm{S}_{\mathrm{memb}} \sim 1$ and $\mathrm{S}_{\text {molecule }} \leq 0.1, \mathrm{~S}_{\text {dipole-bonded }}$ must be close to 1 . This means that in a bonded malonamide, both carbonyls bonds are parallel. For free malonamides, $\mathrm{S}_{\mathrm{C}=\text { Ofree }}=0$ is explained either by the trans/gauche conformation of carbonyl groups or by the isotropic orientation of molecules within bilayers. Using a Quantum Mechanics method, Boehme et $\mathrm{al}^{35}$ showed that free malonamides, in gas phase, roughly adopt trans conformation ( $\beta$, the angle between the two carbonyl dipoles is $162^{\circ}$ ). The monodentate mode, rarely observed, displays a gauche conformation $\left(\beta\right.$ is about $90^{\circ}$ ). Both conformations would lead to $S_{\text {dipole }}<<1$. However, the bidentate coordination state with lanthanides induces an alignement of carbonyl bonds i.e. cis conformation with $30^{\circ}<\beta<60^{\circ}$ according to the stoichiometry considered. This latter conformation can be considered as the most probable for ion bonded extractants in our system.

The evolution of the carbonyl band shape with the addition of neodymium (figure 8a) enabled to follow quantitatively the complexation. Figure $8 \mathrm{~b}$ display the fraction of bonded carbonyls versus the percentage of neodymium salts in the aqueous solution. In $0.33 \mathrm{M}$ neodymium samples $(100 \%$ of $\mathrm{Li}^{+}$replaced by $\mathrm{Nd}^{3+}$ at constant ionic strength), the DMDBTDMA/Nd ratio is 2 and only $30 \%$ of carbonyls are bonded. Assuming a unique denticity of the coordination complex, the fraction of bonded carbonyls is equal to the fraction of bonded extractants.

\begin{tabular}{c|r|r|r} 
& Free C=0 & Bonded C=0 & CH $_{2}{ }^{*}$ \\
\hline Dichroïc ratio R & 2 & 2.5 & 1.8 \\
\hline $\begin{array}{c}\text { Order } \\
\text { parameter S }\end{array}$ & 0 & 0.096 & 0.106
\end{tabular}

Table 1. Dichroïc ratios of $v_{\mathrm{C}=\mathrm{O}_{f}}, \nu_{\mathrm{C}=\mathrm{O}_{b}}$ and $\boldsymbol{v}_{\mathrm{CH}_{2 S}}$

Order parameters of carbonyls and aliphatics chains. (*Dichroïc ratio of $\mathrm{CH}_{2}$ and order parameter of aliphatic chains).

\section{ANALYSIS - DISCUSSION}

The liquid-liquid extraction of neodymium by DMDBTDMA is usually described by the following solvation reaction ${ }^{36}$, characterized by an equilibrium constant $\mathrm{K}_{\mathrm{T}}$ :

$\overline{\text { DMMDBTDMA }}+\mathrm{Nd}^{3+}+3 \mathrm{NO}_{3}^{-} \Leftrightarrow$

$\overline{(\text { DMDBTDMA })_{\mathrm{x}} \mathrm{Nd}\left(\mathrm{NO}_{3}\right)_{3}}$

where upperlined species are solubilized in the organic phase and the other species are solubilized in water. Usually, above a given bulk concentration in organic phases the extractant forms reverse aggregates which are characterized by their aggregation number (from 4 to $10^{37}$, ${ }^{38}$, depending on concentration, $\mathrm{pH}$, type of salt...). Within these aggregates the coordination number, $\mathrm{x}$, is still under debate since the molecular conformation is not well defined, but it is established that $2<x<4$. However, at a flat interface $\mathrm{x}$ was never determined, neither experimentally nor theoretically. Usually the aggregate size varies between 2 and $3 \mathrm{~nm}^{37,38}$. In our case, it is difficult to consider extractant aggregates within the bilayers as their formation would have induced topological defects that we did not observe by electron or optical microscopies. Moreover, a lower order parameter (closer to zero than 0.1 ) of bonded carbonyls would have been measured with the formation of extractant aggregates. As a consequence, it appears reasonable to consider a $1: 1$ stoechiometry $(\mathrm{x}=1)$ with a bidentate coordination between the ion and the extractant as demonstrated previously.

We propose to describe the solvation reaction in the present system as the sum of three equilibria (Scheme 1):

(1) Positioning of free extractants polar heads at interfaces

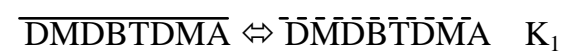

(2) Complexation of cations with extractants at interfaces 


\section{$\overline{\mathrm{D}} \overline{\mathrm{M}} \overline{\mathrm{D}} \overline{\mathrm{B}} \overline{\mathrm{T}} \overline{\mathrm{DM}} \overline{\mathrm{A}}+\mathrm{Nd}^{3+}+3 \mathrm{NO}_{3}^{-} \Leftrightarrow$

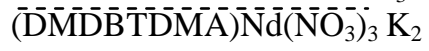

(3) Burying of bonded extractants from interfaces

$$
\begin{aligned}
& \left.{ }^{-} \overline{\mathrm{D}} \overline{\mathrm{M}} \overline{\mathrm{DB}} \overline{\mathrm{T}} \overline{\mathrm{D}} \overline{\mathrm{M}} \overline{\mathrm{A}}\right) \overline{\mathrm{N}} \overline{\mathrm{d}}\left(\overline{\mathrm{NO}} \overline{\mathrm{O}}_{3}\right)_{3} \Leftrightarrow \overline{(\mathrm{DMDBTDMA}) \mathrm{Nd}\left(\mathrm{NO}_{3}\right)_{3}} \\
& \mathrm{~K}_{3}
\end{aligned}
$$

where dash upperlined species are localized at interfaces, and $\mathrm{K}_{\mathrm{i}}$ are the equilibrium constants.

In the next part, we will show that these equilibria can be quantified knowing the concentration of each species.

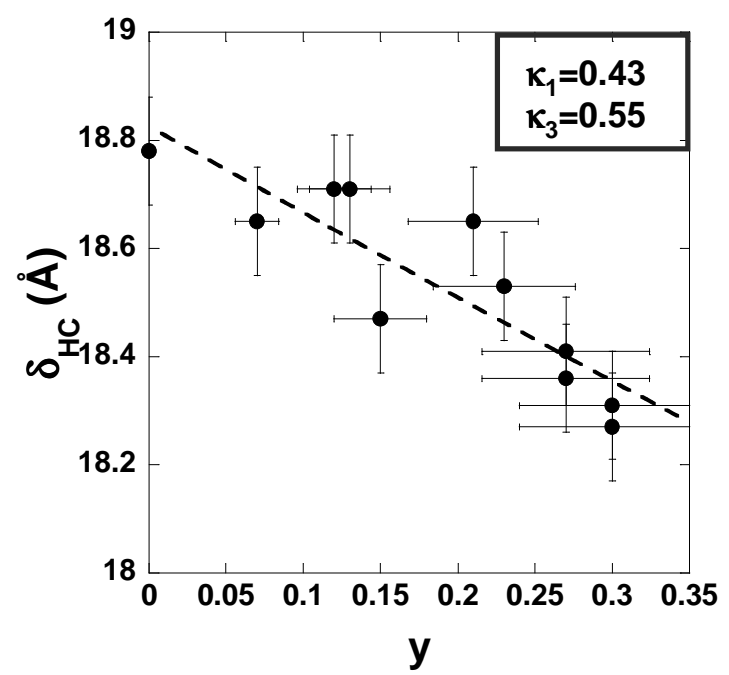

Figure 9. Evolution of bilayer thicknesses $\left(\delta_{\mathrm{HC}}\right)$ versus the fraction of bonded extractant $(\mathrm{y})$. Experimental points are adjusted with equation (20), using $\kappa_{1}=0.43 \pm 0.01$ et $\kappa_{3}=$ $0.55 \pm 0.02$.

The variation in the bilayer thickness can be analysed considering the partition of extractants between the core (as the solvent molecule) and the interface of bilayers (as a cosurfactant), using the following relationship derived from (17):

$\delta_{H C}=\frac{V}{A}=2 \frac{0.8 V_{C_{12}}+0.2 V_{\text {DMDBTDMA }}}{0.8 A_{C_{12} E_{5}}+0.2\left(\kappa_{1}(1-y) \cdot A_{\text {freeDMDBTDMA }}+\kappa_{3} y A_{\text {bondedDMDBTDMA }}\right)}$

where $y$ is the molar fraction of bonded extractants deduced from the FTIR analysis, $\kappa_{1}$ the fraction of free extractants at interfaces and $\kappa_{3}$ the fraction of bonded extractants at interfaces. Each polar head areas was considered constant and was evaluated by tensiometry for DMDBTDMA, and taken from the literature for $\mathrm{C}_{12} \mathrm{E}_{5}$ $\left(\mathrm{A}_{\mathrm{C} 12 \mathrm{E} 5}=50 \AA^{2} / \mathrm{molecule}^{39},{ }^{18}\right.$. Figure 9 displays the evolution of the bilayers thickness as a function of the fraction of bonded extractant, which was adjusted by the equation (20) giving $\kappa_{1}=0.43 \pm 0.01$ and $\kappa_{3}=0.55 \pm 0.02$ (correlation coefficient: 0.8). Approximating extractant activities to molar concentrations, the apparent related equilibrium constants can be calculated using:

$$
K_{1}^{\prime}=\frac{\kappa_{1}}{1-\kappa_{1}} \text { and } K_{3}^{\prime}=\frac{1-\kappa_{3}}{\kappa_{3}}
$$

Hence, $\mathrm{K}^{\prime}{ }_{1}=0.75 \pm 0.3$ and $\mathrm{K}_{3}=0.82 \pm 0.7$. Because of the dispersion of experimental points in the studied scale, values must be used with care. However, this result indicates that bonded extractants, i.e. extractant forming a complex with $\mathrm{Nd}^{3+}$ are more amphiphilic than free extractants. The complexation must charge the lipophilic extractant and should make the head more polar. This is in accordance with tensiometry measurements which display a more important and faster reduction of surface tension with DMDBTDMA in presence of neodymium salt (bonded molecules) than with DMDBTDMA in presence of lithium salt (free extractant).

The complexation of neodymium by DMDBTDMA at the interfaces $\left(\mathrm{K}_{2}\right)$ can be described in a first approach as a cation adsorption isotherm at fluid interfaces. Thus, the Langmuir model can be used:

$$
\theta=\frac{K_{2} a}{1+K_{2} a}
$$

where $\theta$ is the relative occupancy of sites, each site being the polar head of an extractant at interface, $K_{2}$ the adsorption constant, and $a$ the complexing ion activity . The relative occupancy of sites, defined as the ratio between bonded extractants over the total number of extractants at the interface, was determined using FTIR data $(y), \kappa_{1}$ and $\kappa_{3}$ :

$$
\theta=\frac{\kappa_{3} \cdot y}{\kappa_{3} \cdot y+\kappa_{1} \cdot(1-y)}
$$

This definition assumes that the saturation limit of the ion isotherm is $\mathrm{Nd} / \mathrm{DMDBTDMA}=1 / 1$ molar ratio. As previously, the molar concentration was used instead of the ion activity. As a consequence, an apparent adsorption constant $\mathrm{K}_{2}{ }_{2}$ was obtained:

$$
K_{2}^{\prime}=K_{2} \gamma
$$

where $\gamma$ is the molar activity coefficient of the complexing ion ( $a=\gamma C$ where $C$ is the concentration).

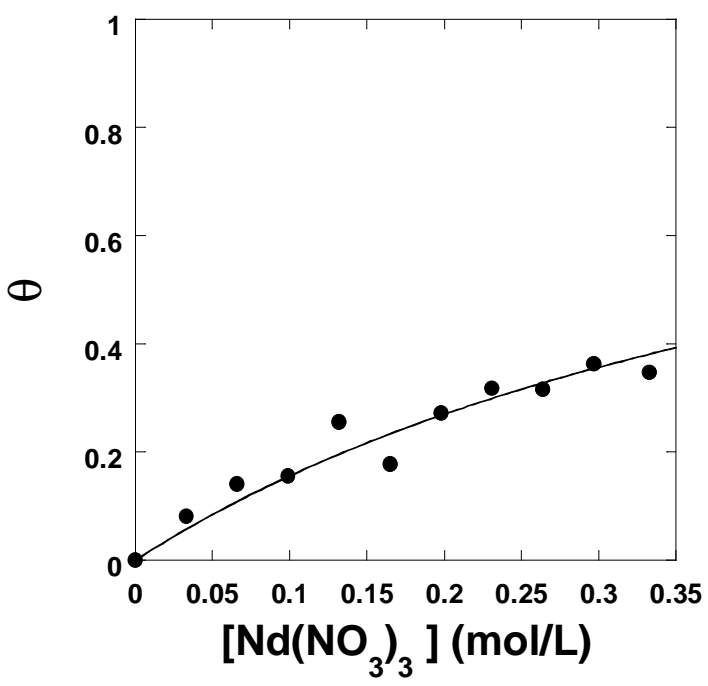

Figure 10. Fraction of bonded extractant at the interface $(\theta)$ as a function of the $\mathrm{Nd}\left(\mathrm{NO}_{3}\right)_{3}$ concentration in the aqueous solution. Experimental points are well fitted with a Langmuir isotherm using $\mathrm{K}_{2}=1.85 \pm 0.3$. 
Figure 10 shows that experimental data were well fitted with such model, using $\mathrm{K}_{2}^{\prime}=1.85 \pm 0.3$.

The apparent equilibrium constants characterizing the system $\left(\mathrm{K}_{1}^{\prime}, \mathrm{K}_{2}{ }_{2}, \mathrm{~K}_{3}{ }_{3}\right)$ deduced from experimental data enabled to calculate the apparent free energy $\left(\Delta \mathrm{G}^{\prime}\right)$ corresponding to the different equilibrium:

$$
\Delta G^{\prime}=-R T \ln K^{\prime}
$$

The different contributions to the free energy are displayed in a table and illustrated by an energy diagram in figure 11. We can observe that the free energy of the total reaction, the ion extraction from the aqueous domains towards the bilayers, is negative due to the complexation (2) reaction which is spontaneous. However this effect is reduced by the energy cost to position the free extractant at the interfaces (1) and to desorb bonded extractant from the interfaces (3), both being energetically unfavourable. The thermodynamics of liquid-liquid extraction by diamides was previously studied in classic biphasic systems. Taking into account the formation of supramolecular aggregates of extractant in the organic phase ${ }^{37,38}$ and their associated potential surfaces on which ions can adsorb, Zemb et $\mathrm{al}^{40,41}$ have obtained thermodynamical extraction parameters assuming a sum of Langmuir isotherms for each state of aggregation. This view enabled to associate thermodynamical values to the different aggregation states of extractants. Free energies of about few $\mathrm{k}_{\mathrm{B}} \mathrm{T}$ were deduced, slightly higher than our values. However, in our model system, we cast off aggregation and only elementary mechanisms at interfaces were studied. Consequently, adsorption constants are not fully comparable. Nevertheless the complexation free energy value can be evaluated looking at the complexation values obtained for hydrosoluble malonamides. Couston et al. $^{42}$ found an 1:1 complexation equilibrium constant $\mathrm{K}_{1: 1}$ equals to 1.3 for tetraethylmalonamides with europium in water. The corresponding free energy value $\left(\Delta \mathrm{G}=-0.26 \mathrm{k}_{\mathrm{B}} \mathrm{T}\right)$ has the same order of magnitude as $\Delta \mathrm{G}_{2}^{\prime}$.

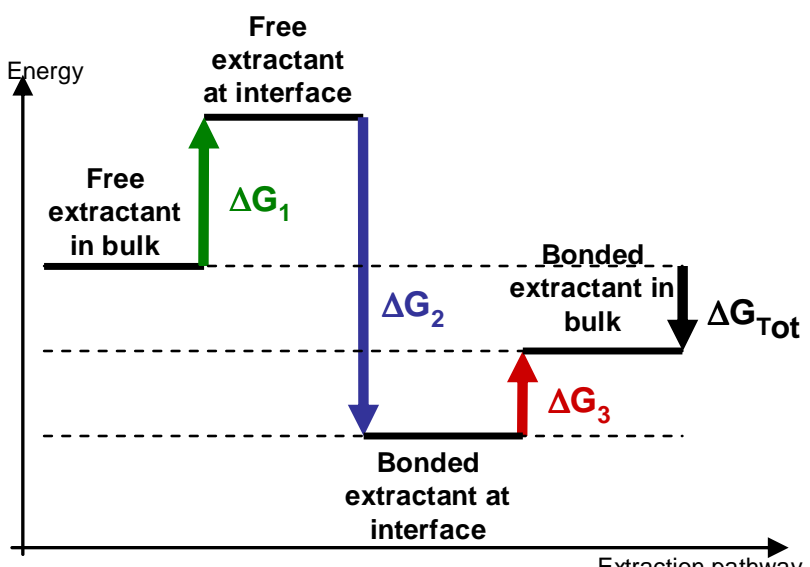

(a)

\begin{tabular}{l|l|l|l|l} 
Equilibrium & $\mathbf{( 1 )}$ & $\mathbf{( 2 )}$ & $\mathbf{( 3 )}$ & Total \\
\hline$\Delta \mathbf{G}(\mathbf{k J} / \mathbf{m o l})$ & 0,69 & $-1,52$ & 0,50 & $-0,33$ \\
\hline$\Delta \mathbf{G}\left(\mathbf{k}_{\mathbf{B}} \mathbf{T}\right)$ & 0,28 & $-0,61$ & 0,20 & $-0,13$
\end{tabular}

Figure 11. (a) Energy diagram of the extraction reaction divided into three elementary equilibrium: positioning of free extractants at interfaces (1), complexation of extractants with cations at interfaces (2), burying of bounded extractants from interfaces (3). (b) Free energy values associated to each elementary steps and to the global extraction reaction.

In our system we use surfactant molecules which must be in competition with extractants for the interfacial adsorption, like in model micellar systems ${ }^{10}$. Thus, the results are certainly function of the surfactant used, but for a given system, parameters such as the nature of extracted cations, the nature of extractant, the ionic force can be studied comparatively. Nevertheless, from these data, the amphiphilic property of extractant could be considered as the limiting step for extraction.

In future studies, the extractant aggregation could be eventually introduced in the lyotropic system releasing sterical constraints by swelling bilayers with oil. In addition, the dehydration of cations, which is included in the mechanism of cation adsorption at interfaces, could be modulated decreasing the water thickness between bilayers. Indeed, the water activity in such confined environments was shown to be modulated by the distance between bilayers $^{43}$. The cation desolvation energy could be thus studied using the lamellar phase.

\section{CONCLUSIONS}

In this work we proposed a lyotropic lamellar phase to study interfacial mechanisms of liquid-liquid extraction. Due to the numerous oriented interfaces and using a combination of SAXS and FTIR techniques, we determined the concentrations of free and bonded extractants molecules either buried into bilayers or localized and oriented at interfaces,. Hence, apparent free energies associated to each interfacial elementary mechanism were estimated. Results indicate that extraction by DMDBTDMA is partially controlled by the variation of amphiphilicity of the molecule during the ion complexation. Between bonded and free extractant, the former appears to be a more favourable state at interfaces. This observation could be considered as a bridle to an ideal extraction kinetics.

With this study we demonstrated that a lyotropic lamellar phase can be a meaningful system to model reactive liquidliquid interfaces. In the future, other studies could be engaged varying parameters such as the nature of reactants or layers thicknesses.

\section{ACKNOWLEDGMENTS}

We thank Thomas Zemb, Laurence Berthon and MarieChristine Charbonnel for stimulating discussions, David Maurin for his assistance during polarized FTIR-ATR experiments, Olivier Mondain Monval for his expertise on cryofracture observations, Jérôme Maynadié for his help during deuteration of neodymium salts and Gaëlle GassinMartin for fruitful discussions concerning tensiometry measurements. We also thank Daniel Meyer for fruitful discussion on ion coordination with extractant molecules. 
This work was supported by the European ACSEPT network.

\section{REFERENCES}

(1) Liquid interfaces in chemical, biological, and pharmaceutical applications; Volkov, A. G., Ed.; Marcel Dekker, New York, 2001.

(2) Fiamegos, Y.; Stalikas, C. Anal. Chim. Acta 2005, 550, 1-12.

(3) Zhang, J.; Meng, X.-G.; Zeng, X.-C.; Yu, X.-Q. Coord. Chem. Rev. 2009, 253, 2166-2177.

(4) Reis, P.; Holmberg, K.; Watzke, H.; Leser, M.; Miller, R. Adv. Colloid Interface Sci. 2009, 147-148, 237 - 250.

(5) Jeribi, M.; Almir-Assad, B.; Langevin, D.; Henaut, I.; Argillier, J. J. Colloid Interface Sci. 2002, 256, 268-272.

(6) Zarbakhsh, A.; Webster, J. R. P.; Wojciechowski, K. Langmuir 2009, 25, 11569-11575.

(7) Watanabe, M. Anal. Chem. 2009, 81, 8213-8218.

(8) Li, Q.; Xie, S.; Liang, Z.; Meng, X.; Liu, S.; Girault, H. H.; Shao, Y. Angew. Chem. Int. Ed. 2009, 48, 8010-8013.

(9) Mircheva, K.; Minkov, I.; Ivanova, T.; Panaiotov, I.; Proust, J.; Verger, R. Colloids Surf., B 2008, 67, 107 - 114.

(10) Tondre, C.; Hebrant, M.; Watarai, H. J. Colloid Interface Sci. 2001, 243, 1 - 10 .

(11) Petrache, H. I.; Zemb, T.; Belloni, L.; Parsegian, V. A. Proc Natl Acad Sci U S A 2006, 103, 7982-7987.

(12) Aroti, A.; Leontidis, E.; Dubois, M.; Zemb, T. Biophys. J. 2007, 93, 1580-1590.

(13) Leontidis, E.; Aroti, A.; Belloni, L.; Dubois, M.; Zemb, T. Biophys. J. 2007, 93, 1591-1607.

(14) Ladbrook.BD,; Williams, R.; Chapman, D. Biochim. Biophys. Acta 1968, 150, 333-\&.

(15) Tamai, N.; Uemura, M.; Goto, M.; Matsuki, H.; Kaneshina, S. Colloids Surf., B 2008, 65, 213-219.

(16) Mills, T. T.; Tristram-Nagle, S.; Heberle, F. A.; Morales, N. F.; Zhao, J.; Wu, J.; Toombes, G. E. S.; Nagle, J. F.; Feigenson, G. W. Biophys. J. 2008, 95, 682-690.

(17) Dhez, O.; Konig, S.; Roux, D.; Nallet, F.; Diat, O. Eur. Phys. J. E 2000, 3, 377-388.

(18) Banc, A.; Bauduin, P.; Diat, O. Chem. Phys. Lett. 2010.

(19) Advanced separation techniques for nuclear fuel reprocessing and radioactive waste treatment; Nash, K. L., Lumetta, G. J., Eds.; 2010.

(20) Estler, F.; Eickerling, G.; Herdtweck, E.; Anwander, R. Organometallics 2003, 22(6), 1212-1222.
(21) Tian, Q.; Hugues, M. Hydrometallurgy 1994, 36(3), 315330 .

(22) Tchakalova, V.; Testard, F.; Wong, K.; $\quad$ Parker, A.; Benczédi, D.; Zemb, T. Colloids Surf., A 2008, 331, 40 - 47.

(23) Li, Y.; Beck, R.; Huang, T.; Choi, M. C.; Divinagracia, M. J. appl. crystallogr. 2008, 41, 1134-1139.

(24) Harrick, N. J.; du Pré, F. K. Appl. Opt. 1966, 5, 1739-1743.

(25) Harrick, N. J. Opt. Soc. Am. 1965, 55, 851-857.

(26) Mitchell, D. J.; Tiddy, G. J. T.; Waring, L.; Bostock, T.; McDonald, M. P. J. Chem. Soc., Faraday Trans. 1 1983, 79, 975 -1000 .

(27) Varade, D.; Kunieda, H.; Strey, R.; Stubenrauch, C. J. Colloid Interface Sci. 2006, 300, 338-347.

(28) Moreau, P.; Navailles, L.; Giermanska-Kahn, J.; MondainMonval, O.; Nallet, F.; Roux, D. Europhys. Lett. 2006, 73, 49-54.

(29) Tanford, C. J. Phys. Chem. 1972, 76, 3020-3024.

(30) Dozol, H.; Berthon, C. C. R. Chim. 2006, 9, 556-563.

(31) Martinet, L. Ph.D. thesis, Université Paris XI, 2005.

(32) Tonegawa, A.; Ohno, K.; Matsuura, H.; Yamada, K.; Okuda, T. J. Phys. Chem. B 2002, 106, 13211-13223.

(33) Rothschild, K.; Clark, N. Biophys. J. 1979, 25, 473-487.

(34) Ivanov, D.; Dubreuil, N.; Raussens, V.; Ruysschaert, J.-M.; Goormaghtigh, E. Biophys. J. 2004, 87, 1307-1315.

(35) Boehme, C.; Coupez, B.; Wipff, G. J. Phys. Chem. A 2002, 106, 6487-6498.

(36) Weigl, M.; Geist, A.; Gompper, K.; Kim, J. Solvent Extr. Ion Exch. 2001, 19, 215-229.

(37) Erlinger, C.; Belloni, L.; Zemb, T.; Madic, C. Langmuir 1999, 15, 2290-2300.

(38) Testard, F.; Bauduin, P.; Martinet, L.; Abecassis, B.; Berthon, L.; Madic, C.; Zemb, T. Radiochim. Acta 2008, 96, 265272.

(39) Rosen, M.; Cohen, A.; Dahanayake, M.; Hua, X. J. Phys. Chem. 1982, 86, 541-545.

(40) Testard, F.; Berthon, L.; Zemb, T. C. R. Chim. 2007, 10, $1034-1041$.

(41) Meridiano, Y. Ph.D. thesis, Université Paris XI - Orsay, 2009.

(42) Couston, L.; Charbonnel, M.-C.; Flandin, J.-L.; Moulin, C.; Rancier, F. Radiochim. Acta 2004, 92, 1-8.

(43) Lyle, I.; Tiddy, G. Chem. Phys. Lett. 1986, 124, 432-436. 